\title{
Fermentation and bulking capacity of indigestible carbohydrates: the case of inulin and oligofructose
}

\author{
M. Nyman* \\ Applied Nutrition and Food Chemistry, Center for Chemistry and Chemical Engineering, PO Box 124, \\ Lund University, SE-22100- Lund, Sweden
}

\begin{abstract}
The bulking index (i.e. the increase in faecal fresh weight in gram per gram indigestible carbohydrate ingested) with oligofructose and inulin is similar to that produced with other easily fermented fibres such as pectins and gums. Most studies in man have been performed at a level of $15 \mathrm{~g} / \mathrm{d}$ and more investigations on lower intakes are needed to appoint the least intake for an effect. Concerning short-chain fatty acids (SCFA) most studies have been using oligofructose and points at an increased butyric acid formation in the caecum of rats. In one study on rats with inulin high caecal proportions of propionic acid were obtained. As inulin has a higher molecular weight than oligofructose it might be speculated if this could be a reason to the different SCFA-profile formed. No effects on faecal concentrations of SCFA in humans have been revealed with inulin and oligofructose, which neither is expected as most of the SCFA formed during the fermentation already has been absorbed or utilized by the colonic mucosa.
\end{abstract}

Bulking index: SCFA: Inulin: Oligofructose

\section{Introduction}

Carbohydrates, which are not digested nor utilized in the small intestine, reach the large intestine where they can be partly or totally degraded by the microflora. During this fermentation short-chain fatty acids (SCFA), mainly acetic-, propionic- and butyric acid, and gases are formed (Macfarlane \& Cummings, 1991). Carbohydrates resistant to fermentation usually have a high bulking effect, thus reducing the risk for constipation and possibly also colonic cancer (Cummings et al. 1992). Easily fermentable carbohydrates, on the other hand, may also be of nutritional interest as some of the short-chain fatty acids formed have been suggested to be of physiological importance. Butyric acid is the preferred energy substrate for the colonic mucosa and has been suggested to protect against colonic disease, e.g. ulcerative colitis and cancer (Scheppach et al. 1992; Lupton, 1995; Gamet et al. 1992). The proportion of propionic- and acetic acid, on the other hand, appears to affect glucose- and lipid metabolism beneficially and the higher the amount of propionic acid the more pronounced are the effects (Wolever et al. 1991). An increase in the SCFA-formation also leads to a decreased $\mathrm{pH}$ that may stimulate mineral absorption in the colon and increase the blood flow.
The most well-known source of indigestible carbohydrates are the non-starch polysaccharides. Other examples are the oligosaccharides like the fructans found in, for example onion, chicory and artichoke and the $\alpha$-galactosides found in legumes as well as some starch fractions that for various reasons may reach the colon undigested.

\section{Bulking capacity}

Carbohydrates resistant to bacterial fermentation increase the bulk passing through the colon. For some of the resistant types of carbohydrates, the capacity to hold water may add to this effect. Different types of carbohydrates are fermented to various degrees, and factors of importance are, for example the monomeric composition of the saccharides and type of glycosidic linkages present (Nyman, 1985). The degree of polymerization, the solubility and the structural arrangement of the carbohydrates may also be important for the degree of fermentation. Food processing may change some of these properties, and as a result the fermentability and the bulking effects will be altered (Svanberg et al. 1995).

\footnotetext{
Abbreviations: SCFA, short-chain fatty acids.

Note: For the definition of the terms inulin and oligofructose please refer to the introductory paper (p. S139) and its footnote.

*Corresponding author: Dr M. Nyman, fax +46 4622245 32, email Margareta.Nyman@inl.lth.se
} 
Table 1. Bulking capacity of inulin and oligofructose compared to some other indigestible carbohydrates in rats and humans

\begin{tabular}{|c|c|c|c|c|c|}
\hline Carbohydrate & Level ${ }^{*}$ & $\begin{array}{l}\text { Duration } \\
\text { (days) }\end{array}$ & Model & $\begin{array}{l}\text { Bulking } \\
\text { index }\end{array}$ & Reference \\
\hline Oligofructose & 10 & 18 & Rats, $n=5$ & $1 \cdot 1$ & Roberfroid et al. 1993 \\
\hline Inulin & 10 & 17 & Rats, $n=5$ & $1 \cdot 2$ & \\
\hline Wheat bran & $10 \cdot 9$ & 24 & Rats, $n=12$ & $1.1 \S$ & Hansen et al. 1992 \\
\hline Oat bran & $11 \cdot 2$ & 24 & Rats, $n=12$ & $0.6 \S$ & \\
\hline Pea fibre & $12 \cdot 3$ & 24 & Rats, $n=12$ & $0.2 \S$ & \\
\hline Ispaghula & 10 & 9 & Rats, $n=5$ & $1.0 \S$ & Nyman \& Asp, 1985 \\
\hline Sterkulia & 10 & 9 & Rats, $n=5$ & $1.4 \S$ & \\
\hline Wheat bran & 4.9 & 9 & Rats, $n=5$ & $1.3,0.8 \S$ & Nyman \& Asp, 1982 \\
\hline Guar gum & $9 \cdot 0$ & 9 & Rats, $n=5$ & $0.5,0.3 \S$ & \\
\hline Pectin & 7.5 & 9 & Rats, $n=5$ & $1.4,0.5 \S$ & \\
\hline Sugar-beet fibre & 7.4 & 9 & Rats, $n=5$ & $1.2,0.5 \S$ & \\
\hline Wheat bran & $4 \cdot 2$ & 28 & Rats, $n=6$ & $2 \cdot 2$ & Armstrong et al. 1993 \\
\hline Pectin & $9 \cdot 2$ & 28 & Rats, $n=6$ & 1.0 & \\
\hline Oligofructose & 15 & 15 & Humans, $n=8$ & $1 \cdot 2$ & Gibson et al. 1995 \\
\hline Inulin & 15 & 15 & Humans, $n=4$ & $2 \cdot 1$ & \\
\hline Inulin & $3 \times 5$ & 14 & Humans, $n=6$ & 1.5 & Den Hond et al. 2000 \\
\hline Sugarbeet-fibre & 50 & $16+8$ & Humans, $n=9$ & 1.5 & Castiglia-Delavaud et al. 1998 \\
\hline Inulin & 50 & & Humans, $n=9$ & 1.5 & \\
\hline Ordinary diet & $40+0$ & 7 & Humans, $n=24$ & No-effect & Alles et al. 1996 \\
\hline Oligofructose & $40+5$ & 7 & Humans, $n=24$ & & \\
\hline Oligofructose & $40+15$ & 7 & Humans, $n=24$ & & \\
\hline Control & 0 & 21 & Humans, $n=12$ & No-effect & Van Dokkum et al. 1999 \\
\hline Inulin & 15 & 21 & Humans, $n=12$ & & \\
\hline Oligofructose & 15 & 21 & Humans, $n=12$ & & \\
\hline Galacto-oligosaccharides & 15 & 21 & Humans, $n=12$ & & \\
\hline
\end{tabular}

* Level of indigestible carbohydrate in the diet given to rats is represented in $\mathrm{g} / 100 \mathrm{~g}$.

† Level of daily intake in humans is represented in $\mathrm{g}$.

¥ Increase in faecal wet weight in gram per gram added indigestible carbohydrate.

$\S$ Increase in faecal dry weight in gram per gram added indigestible carbohydrate.

\section{Animal studies}

From in vivo studies on rats it can be concluded that the extent of fermentation varies for different types of nonstarch polysaccharides and resistant starches. Cellulose, oat husk, ispaghula and sterkulia are examples of nonstarch polysaccharides that are highly resistant against microbial degradation, whereas $\beta$-glucans, pectins and gums are rapidly fermented (Nyman \& Asp, 1985; Berggren et al. 1993). Similarly native resistant starch has been reported to be less fermented than retrograded starch (Schultz et al. 1993). Oligosaccharides, on the other hand, seem to be more or less completely fermented (Berggren et al. 1993). Nevertheless, easily fermentable types of carbohydrates have been reported to have a certain faecal bulking effect, due to an increased bacterial mass (Macfarlane \& Cummings, 1991). Thus, bulking index (i.e. increase in fresh faecal weight in $\mathrm{g} / \mathrm{g}$ of indigestible carbohydrates eaten) for pectin has been shown to be around one (Table 1), while that with wheat bran has been reported to be between 1.3 and 2.2 (Armstrong et al. 1993; Hansen et al. 1992; Nyman \& Asp, 1982). The comparatively low bulking index of wheat bran is due to its low capacity to hold water. Bulking index for inulin and oligofructose when fed at a similar level as wheat bran and pectin has been reported to be around one (Roberfroid et al. 1993). However, the bulking index obtained in rats must be interpreted with care and cannot necessarily be expected to be indicative for man. It is difficult to determine faecal wet weight accu- rately in rats and human faeces are generally much smoother with higher water content than faeces of rats. A more relevant measure when extrapolating rat data to humans is probably faecal dry weight increment per gram of fibre taken. Both fibre fermentability and faecal dry weight increment per gram of fibre taken has been shown to be well correlated between humans and rats (Nyman et al. 1986).

\section{Human studies}

Most studies in humans use six to twelve healthy volunteers, and the subjects have been given doses of $15 \mathrm{~g}$ indigestible carbohydrates per day for 2-5 weeks. Exclusion criteria for the studies have been use of antibiotics for at least the last 6 months and previous gut disorders.

When oligofructose was given to healthy volunteers $(N=8)$ the bulking index was reported to be between 1.0 and 1.2 (Gibson et al. 1995) but inulin, induced a higher bulking index of $2 \cdot 1$. However, as very few persons participated in the study $(n=4)$ it is difficult to draw any conclusion about the influence of the molecular weight. A very similar bulking index as with oligofructose $(1.5)$ was also obtained when inulin with a higher chain length (average $\mathrm{DP}=25$ ) was given in doses of $5 \mathrm{~g}$ three times daily to slightly constipated volunteers (Den Hond et al. 2000), suggesting minor importance of the molecular weight on faecal bulking capacity. Neither a higher dose had any effect and such a high dose as $50 \mathrm{~g}$ gave a very similar 
Table 2. SCFA formed at fermentation of inulin and oligofructose compared to some other indigestible carbohydrates by human faecal bacteria in vitro, in the rat caecum or in human faeces

\begin{tabular}{|c|c|c|c|c|c|c|c|c|c|}
\hline \multirow[b]{2}{*}{ Carbohydrate } & \multirow[b]{2}{*}{ Level } & \multirow[b]{2}{*}{ Duration* $†$} & \multicolumn{4}{|c|}{ SCFA concentration $\ddagger \S^{* \star} † \dagger \ddagger \ddagger$} & \multirow{2}{*}{$\begin{array}{l}\text { SCFA-profile (\%) } \\
\quad \mathrm{C}_{2}: \mathrm{C}_{3}: \mathrm{C}_{4}\end{array}$} & \multirow[b]{2}{*}{ Model } & \multirow[b]{2}{*}{ Reference } \\
\hline & & & Acetate & Propionate & Butyrate & Lactate & & & \\
\hline Oligofructose $\ddagger$ & 6 & 14 & 35.7 & 4.69 & 10.53 & 0.30 & 70:9:21 & Rats, $n=10$ & Campbell et al. 1997 \\
\hline Oligofructose (from sucrose) $\ddagger$ & 6 & 14 & 44.64 & 5.44 & 9.74 & 0.54 & $75: 9: 16$ & & \\
\hline Xylooligosaccharides $\ddagger$ & 6 & 14 & $35 \cdot 34$ & 4.90 & 5.95 & 1.30 & $76: 11: 13$ & & \\
\hline Oligofructose§ & 10 & 56 & 31.42 & 8.65 & 14.83 & 1.65 & $57: 16: 27$ & $\begin{array}{l}\text { Germ-free rats inoculated } \\
\text { with human faecal flora, } \\
n=6\end{array}$ & Roland et al. 1995 \\
\hline Carrot§ & 10 & 56 & $32 \cdot 16$ & 8.80 & 3.66 & 2.63 & 72:20:8 & & \\
\hline Wheat bran§ & 10 & 56 & 28.40 & 9.42 & $4 \cdot 14$ & 1.63 & 68:22:10 & & \\
\hline Pea§ & 10 & 56 & 23.91 & 9.44 & $3 \cdot 12$ & $1 \cdot 10$ & $66: 26: 8$ & & \\
\hline Oats§ & 10 & 56 & $23 \cdot 27$ & $9 \cdot 15$ & $3 \cdot 20$ & 2.01 & $65: 26: 9$ & & \\
\hline Inulin $\ddagger$ & 0 & 21 & $54 \cdot 6$ & $19 \cdot 8$ & $10 \cdot 3$ & 0 & $65: 23: 12$ & Rats, $n=12$ & Levrat et al. 1991 \\
\hline Inulin‡ & 5 & 21 & $64 \cdot 7$ & $47 \cdot 8$ & 30.6 & $<5$ & $45: 34: 21$ & & \\
\hline Inulin $\ddagger$ & 10 & 21 & $66 \cdot 2$ & 58.4 & 31.0 & $19 \cdot 3$ & $42: 38: 20$ & & \\
\hline Inulin $\ddagger$ & 20 & 21 & $42 \cdot 6$ & 35.9 & $28 \cdot 1$ & 30.7 & $40: 34: 26$ & & \\
\hline Oligofructose (from sucrose) & - & - & - & - & - & - & $62: 13: 25$ & In vitro, $6 \mathrm{~h}$ & Luo et al. 1996 \\
\hline Lactulose & - & - & - & - & - & - & $74: 7: 19$ & & \\
\hline Oligofructose & - & - & - & - & - & - & $65: 22: 13$ & In vitro, $6 \mathrm{~h}$ & Clausen et al. 1998 \\
\hline Lactulose & - & - & - & - & - & - & $64: 22: 14$ & & \\
\hline Oligofructose ${ }^{\star \star}$ & 15 & 15 & $76 \cdot 8$ & 23.0 & 18.5 & - & $65: 20: 15$ & Humans, $n=8$ & Gibson et al. 1995 \\
\hline Sucrose $e^{\star \star}$ & 15 & 15 & $64 \cdot 3$ & $21 \cdot 8$ & $16 \cdot 0$ & - & $64: 21: 15$ & & \\
\hline Placebot† & - & 7 & $22 \cdot 8$ & 3.6 & $2 \cdot 3$ & - & $80: 12: 8$ & $\begin{array}{l}\text { Humans with ileal pouch-anal } \\
\text { anastomosis, } n=16\end{array}$ & Alles et al. 1997 \\
\hline Oligofructoset† & $14 \cdot 3$ & 7 & $25 \cdot 2$ & $2 \cdot 8$ & 2.9 & - & $82: 9: 9$ & & \\
\hline Resistant starch†† & $14 \cdot 3$ & 7 & 26.7 & 3.4 & 3.9 & - & $79: 10: 11$ & & \\
\hline Inulinł‡ & 20 & 7 & 137.5 & 60.5 & 33.1 & $6 \cdot 0$ & $60: 26: 14$ & $\begin{array}{l}\text { Humans, } n=10 \\
\text { Humans, } n=15\end{array}$ & Kleessen et al. 1997 \\
\hline Inulinłł & 40 & 7 & $114 \cdot 3$ & $42 \cdot 3$ & 31.6 & 8.0 & $61: 22: 17$ & & \\
\hline Lactoseł‡ & 20 & 7 & $137 \cdot 6$ & $45 \cdot 4$ & $49 \cdot 0$ & $5 \cdot 7$ & $59: 20: 21$ & & \\
\hline Lactoseł‡ & 40 & 7 & 133.4 & 39.0 & 34.7 & 6.0 & $64: 19: 17$ & & \\
\hline Rice $^{\star \star}$ & $20 \cdot 4$ & 28 & 42.93 & 14.87 & $15 \cdot 28$ & $3 \cdot 21$ & $59: 20: 21$ & Humans $n=12$ & Brighenti et al. 1999 \\
\hline Inulin** & 19.5 & 28 & 33.26 & 11.99 & $12 \cdot 82$ & 7.39 & $57: 21: 22$ & & \\
\hline Oligofructoseł & 40 & 3 & 73 & 18 & 19 & 2 & $67: 16: 17$ & Humans, $n=12$ & Clausen et al. 1998 \\
\hline Oligofructose & 80 & 3 & 87 & 14 & 19 & 28 & $72: 12: 16$ & & \\
\hline Lactulose $\ddagger$ & 40 & 3 & 72 & 14 & 17 & 9 & $70: 14: 16$ & & \\
\hline Lactulose & 80 & 3 & 80 & 9 & 12 & 28 & $79: 9: 12$ & & \\
\hline
\end{tabular}

*Level of indigestible carbohydrate in the diet given to rats is represented in $\mathrm{g} / 100 \mathrm{~g}$.

tevel of daily intake in humans is represented in $\mathrm{g}$.

SCFA-concentration in caecum of rats in $\mathrm{mmol} / \mathrm{l}$.

$\S$ SCFA-concentration in caecum of rats in $\mathrm{mmol} / \mathrm{g}$.

** SCFA-concentration in $\mathrm{mmol} / \mathrm{kg}$ wet faeces.

†† SCFA concentration in faeces in $\mathrm{mmol} / \mathrm{d}$. 
bulking index as the lower doses used (Castiglia-Delavaud et al. 1998).

Due to a high production of gases during the fermentation of easily fermentable carbohydrates high levels of oligosaccharides can lead to intestinal discomfort. Therefore it may be interesting to know the minimum dose to obtain an effect. Not many studies have been performed at levels lower than $15 \mathrm{~g} / \mathrm{d}$, but Menne et al. (2000) concluded a tendency to confirmation of the bulking effect previously reported, with only $8 \mathrm{~g}$ oligofructose per day. They also reported a change in stool frequency and appearance (softer) of the stool. Further, an increased stool weight and stool frequency has been reported with oligofructose (from sucrose) at levels as low as $3 \mathrm{~g} / \mathrm{d}$ for subjects having a low stool frequency (Tominaga et al. 1999).

The bulking index obtained with inulin and oligofructose thus seems to be in the similar range as reported for easilyfermented types of dietary fibre such as pectin $(1-2)$, guar gum (1-2) and sugar-beet fibre (1.5) (Cummings, 1984; Spiller, 1993; Castiglia-Delavaud et al. 1998), but lower than that of wheat bran $(2 \cdot 5-5)$, one frequently consumed resistant type of fibre (Cummings, 1984; Spiller, 1993; Spiller et al. 1986). The laxative effect of inulin has also been reported to be better, as judged by the higher stool frequency, than with lactose in constipated elderly, when given in doses from 20 to $40 \mathrm{~g}$ (Kleessen et al. 1997). In contrast, other studies have reported minor effects with oligofructose and inulin (Alles et al. 1996; van Dokkum et al. 1999). Thus, faecal weight was not affected in healthy men when added to the ordinary diet at a level of 5 and $15 \mathrm{~g} / \mathrm{d}$, which could be due to the fact that these patients already had a high intake of non-starch polysaccharides (40 g/d) (Alles et al. 1996).

In conclusion, inulin and oligofructose seem to have a similar bulking effect as gums and pectins. However, more large-scale studies are needed. Further, most studies have been performed on inulin and oligofructose at a level of $15 \mathrm{~g} / \mathrm{d}$ or more. Further studies on lower intakes are therefore needed.

\section{Short-chain fatty acids}

The pattern of short-chain fatty acids (SCFA) formed upon fermentation of easily fermentable carbohydrates is another factor of nutritional importance. Butyric acid appears to be essential in the maintenance of a healthy colonic mucosa, whereas propionic acid is increasingly connected with beneficial effects on carbohydrate and lipid metabolism. SCFA may also influence colonic motility. Of special interest is that various indigestible carbohydrates give rise to different SCFA patterns (Berggren et al. 1993). This might be due to the fact that the substrate favours growth of colonic bacteria, producing a specific short-chain fatty acid pattern.

The formation of SCFA is not that easy to measure and different methodologies are used to analyse the formation and pattern of short-chain fatty acids. Studies in humans focus on the SCFA found in faeces, and not at the actual site for fermentation. To enable evaluation of SCFA production from various substrates, relevant experimental models are therefore needed. Examples of such models are in vitro incubations with human or animal faeces, or animal studies. Studies in rats mostly focus on shortchain fatty acid pattern in the caecum.

\section{Animal studies}

Particularly high amounts of propionic acid have been obtained with guar gum, and nearly $30 \%$ of the SCFA has been shown to be propionic acid, whereas $\beta$-glucans, raffinose and oligofructose (from sucrose) promoted a high production of butyric acid (15-22\%) (Berggren et al. 1993). Interestingly, dietary fibre rich in uronic acids (pectin and linseed fibre) gave very low levels of butyric acid, only 7 or $4 \%$, respectively. This is noteworthy, in light of the fact that uronic acid containing fibres, like pectin but also fibre isolated from carrots, appear to stimulate chemically induced cancer in rats (Bauer et al. 1981).

Inulin and oligofructose, appear to be highly fermented both in vitro and in vivo, yielding high levels of shortchain fatty acids. Most studies have been performed on oligofructose (Table 2). Thus, in a study on rats, oligofructose at a level of $6 \mathrm{~g} / 100 \mathrm{~g}$, gave a higher caecal concentration of butyrate $(10.53$ and $9.74 \mathrm{mmol} / \mathrm{l})$ compared with the same amount of xylo-oligosaccharides $(5.95 \mathrm{mmol} / \mathrm{l})$ (Campbell et al. 1997). No significant differences were obtained in the concentration of acetate, propionate or lactate. Similarly, in a study on germ-free rats, inoculated with human faecal flora, oligofructose $(10 \mathrm{~g} / 100 \mathrm{~g})$ gave a four-fold increase in caecal concentration of butyrate $(14.83 \mathrm{mmol} / \mathrm{g})$ compared to $3.66,4.14,3.12$ or $3.20 \mathrm{mmol} / \mathrm{g}$ for dietary fibre from carrots, wheat bran, peas and oats, respectively (Roland et al. 1995). However, all these food items, except carrots, are relatively resistant against fermentation that may explain the low caecal concentrations of SCFA. The amount of propionate was not affected by diet in this study either, while the yield of acetate was lower with peas and oats than in the other materials. A significantly higher caecal concentration of butyrate with oligofructose has also been obtained by Poulsen \& Mølck (2002). They found that there was a significant increase in butyrate concentration when rats were given oligofructose $(15 \mathrm{~g} / 100 \mathrm{~g})$ for 5 or 10 weeks, independently if the rats were administered with dimethylhydrazine or not, compared with the other groups studied (inulin $5 \mathrm{~g} / 100 \mathrm{~g}$ and $15 \mathrm{~g} / 100 \mathrm{~g}$ or oligofructose $5 \mathrm{~g} / 100 \mathrm{~g}$ ).

Some studies have also been performed on inulin. There was a significant dose-dependent increase in the total amount of caecal SCFA and of lactic acid when rats received inulin at the level of $0,5,10$ or $20 \mathrm{~g} / 100 \mathrm{~g}$ (Levrat et al. 1991). The proportion of propionic acid formed was very high (34-38\%) compared with studies on oligofructose, and it may be speculated that the higher molecular weight of inulin is a reason for this. The high level of lactic acid formed at the level of $20 \mathrm{~g} / 100 \mathrm{~g}$ with inulin led to very acidic conditions ( $\mathrm{pH}$ 5.65) and as proposed by the authors to an accelerated absorption of SCFA.

\section{In vitro studies}

Studies in vitro, with human faecal inoculum, have also 
shown that different substrates give various SCFA patterns. Starch has been shown to yield high proportions of butyric acid, and arabinogalactans high proportions of propionic acid (Englyst et al. 1987). In vitro fermentation of oligofructose (from sucrose) resulted in higher molar ratios of propionate and butyrate (13 and $25 \%$, respectively) than with lactulose (7 and 19\%, respectively) (Luo et al. 1996), but lower than many types of starches (Ferguson \& Jones, 2000). However, Clausen et al. (1998) found very similar proportions of acetate, propionate and butyrate with both lactulose and oligofructose.

\section{Human studies}

Generally no effect on faecal concentration or of molar proportions of acetate, propionate and butyrate has been seen with inulin or oligofructose in humans (Gibson et al. 1995; Alles et al. 1996; Alles et al. 1997; Kleessen et al. 1997; Clausen et al. 1998; Brighenti et al. 1999; Kruse et al. 1999). However, an increased concentration of lactic acid at higher doses $(80 \mathrm{~g} / \mathrm{d})$ has been reported (Clausen et al. 1998). Further, in the study by Kleessen et al. (1997) the proportion of butyrate tended to be higher at the higher doses $(40 \mathrm{~g} v .20 \mathrm{~g})$ with inulin, but these data are a bit confusing.

In conclusion, most studies on SCFA have used oligofructose and points at an increased amount of butyric acid in the caecum of rats. In humans no effects on faecal SCFA can be seen. In one study on rats using inulin very high proportions of propionic acid were obtained, and more studies on inulin are therefore needed. Although inulin is completely fermented the degradation may be slower than with oligofructose, which might give rise to another SCFA pattern. Changes in SCFA pattern may also be reflected in faeces with a slowly fermentable carbohydrate. The place of fermentation is important to evaluate, as most colonic diseases appear in the distal end. It is important to study the SCFA pattern of fructo-oligosaccharides in combinations with other food items.

\section{References}

Alles MS, Hautvast JGA, Nagengast FM, Hartemink R, van Laere KMJ \& Jansen JBMJ (1996) Fate of fructo-oligosaccharides in the human intestine. British Journal of Nutrition 76, 211-221.

Alles MS, Katan MB, Salemans JMJI, van Laere KMJ, Gerichhausen MJW, Rozendaal MJ \& Nagengast FM (1997) Bacterial fermentation of fructooligosaccharides and resistant starch in patients with an ileal pouch anal anastomosis. American Journal of Clinical Nutrition 66, 1286-1292.

Armstrong EF, Eastwood MA \& Brydon WG (1993) The influence of wheat bran and pectin on the distribution of water in rat cecal contents and feces. British Journal of Nutrition 69, 913-920.

Bauer HG, Asp NG, Dahlqvist A, Fredlund PE, Nyman M \& Öste R (1981) Effect of two kinds of pectin and guar gum on 1,2-dimethylhydrazine initiation of colon tumors and on fecal $\beta$-glucuronidase activity in the rat. Cancer Research 41, $2518-2523$.

Berggren AM, Björck IME, Nyman EMGL \& Eggum BO (1993) Short-chain fatty acid content and $\mathrm{pH}$ in caecum of rats given various sources of carbohydrates. Journal of the Science and Food Agriculture 63, 397-406.

Brighenti F, Casiraghi MC, Canzi E \& Ferrari A (1999) Effect of consumption of a ready-to-eat breakfast cereal containing inulin on the intestinal milieu and blood lipids in healthy male volunteers. European Journal of Clinical Nutrition 53, 726-733.

Campbell JM, Fahey GC \& Wolf BW (1997) Selected indigestible oligosaccharides affect large bowel mass, cecal and fecal short-chain fatty acids, $\mathrm{pH}$ and microflora in rats. Journal of Nutrition 127, 130-136.

Castiglia-Delavaud C, Verdier E, Besle JM, Vernet J, Boirie Y, Beaufrere B, De Baynast R \& Vermorel M (1998) Net energy value of non-starch polysaccharide isolates (sugarbeet fibre and commercial inulin) and their impact on nutrient digestive utilization in healthy human subjects. British Journal of Nutrition 80, 343-352.

Clausen MR, Jørgensen J \& Mortensen PB (1998) Comparison of diarrhea induced by ingestion of fructooligosaccharides Idolax and disaccharide lactulose - role of osmolarity versus fermentation of malabsorbed carbohydrate. Digestive Diseases and Sciences 43, 2696-2707.

Cummings JH (1984) Constipation, dietary fibre and the control of large bowel function. Postgraduate Medical Journal 60, 811-819.

Cummings JH, Bingham SA, Heaton KW \& Eastwood MA (1992) Fecal weight, colon cancer risk, and dietary-intake of nonstarch polysaccharides (dietary fiber). Gastroenterology 103, 1783-1789.

Englyst HN, Hay S \& Macfarlane GT (1987) Polysaccharide breakdown by mixed populations of human faecal bacteria. FEMS Microbial Ecolology 95, 163-171.

Den Hond E, Geypens B \& Ghoos Y (2000) Effect of high performance chicory inulin on constipation. Nutrition Research 20, $731-736$.

Ferguson MJ \& Jones GP (2000) Production of short-chain fatty acids following in vitro fermentation of saccharides, saccharide esters, fructo-oligosaccharides, starches, modified starches and non-starch polysaccharides. Journal of the Science of Food and Agriculture 80, 166-170.

Gamet L, Daviaud D, Denis-Pouxviel C, Remesy C \& Murat JC (1992) Effects of short-chain fatty acids on growth and differentiation of the human colon-cancer cell-line HT29. International Journal of Cancer 52, 286-289.

Gibson GR, Beatty ER, Wang X \& Cummings JH (1995) Selective stimulation of bifidobacteria in the human colon by oligofructose and inulin. Gastroenterology 108, 975-982.

Hansen L, Bach Knudsen K \& Eggum BO (1992) Gastrointestinal implications in the rat of wheat bran, oat bran and pea fibre. British Journal of Nutrition 68, 451-462.

Kleessen B, Sykura B, Zunft H-J \& Blaut M (1997) Effects of inulin and lactose on fecal microflora, microbial activity, and bowel habit in eldery constipated persons. American Journal of Clinical Nutrition 65, 1397-1402.

Kruse HP, Kleessen B \& Blaut M (1999) Effects of inulin on faecal bifidobacteria in human subjects. British Journal of Nutrition 82, 375-382.

Levrat MA, Rémésy C \& Demigné C (1991) High propionic-acid fermentations and mineral accumulation in the cecum of rats adapted to different levels of inulin. Journal of Nutrition 121, 1730-1737.

Luo J, Rizkalla W, Alamowitch C, Boussairi A, Blayo A, Barry JL, Laffitte A, Guyon F, Bornet FRJ \& Slama G (1996) Chronic consumption of short-chain fructooligosaccharides by healthy subjects decreased basal hepatic glucose production but had no effect on insulin-stimulated glucose metabolism. American Journal of Clinical Nutrition 63, 939-945. 
Lupton JR (1995) Short-chain fatty acids and colon tumorigenesis: animal models. In Physiological and Clinical Aspects of Short-Chain Fatty Acids, pp. 307-318 [JH Cummings, JL Rombeau and $\mathrm{T}$ Sakata, editors]. Cambridge: Cambridge University Press.

Macfarlane GT \& Cummings JH (1991) The colonic flora, fermentation, and large bowel digestive function. In The Large Intestine - Physiology, Pathophysiology and Disease, pp. 51-92 [SF Phillips, JH Pemberton and RG Shorter, editors]. New York: Raven Press.

Menne E, Guggenbuhl N \& Roberfroid M (2000) Fn-type chicory inulin hydrolysate has a prebiotic effect in humans. Journal of Nutrition 130, 1197-1199.

Nyman M (1985) Fermentation of dietary fibre in the intestinal tract. PhD thesis, Lund University, Lund.

Nyman M \& Asp NG (1982) Fermentation of dietary fibre in the intestinal tract. British Journal of Nutrition 47, 357-366.

Nyman M \& Asp NG (1985) Bulk laxatives: Their dietary fibre composition, degradation, and faecal bulking capacity in the rat. Scandinavian Journal of Gastroenterology 20, 887-895.

Nyman M, Asp NG, Cummings JH \& Wiggins H (1986) Fermentation of dietary fibre in the intestinal tract - comparison between man and rat. British Journal of Nutrition 55, 487-496.

Poulsen M \& Mølck AM (2002) Different effects of short- and long-chained fructans on large intestinal physiology and carcinogen-induced aberrant crypt foci in rats. Nutrition and Cancer (in press).

Roberfroid M, Gibson GR \& Delzenne N (1993) The biochemistry of oligofructose, a nondigestible fiber - an approach to calculate its caloric value. Nutrition Reviews 51, 137-146.

Roland N, Nugon-Baudon L, Andrieux C \& Szylit O (1995) Comparative study of the fermentative characteristics of inulin and different types of fibre in rats inoculated with a human whole faecal flora. British Journal of Nutrition 74, 239-249.

Scheppach W, Sommer H, Kirchner T, Paganelli GM, Bartram P, Christl S, Richter F, Dusel G \& Kasper H (1992) Effect of butyrate enemas on the colonic mucosa in ulcerative colitis. Gastroenetrology 103, 51-56.

Schultz AG, Van Amelsvoort JM \& Beynen AC (1993) Dietary native resistant starch but not retrograded resistant starch raises magnesium and calcium absorption in rats. Journal of Nutrition 123, 1724-1731.

Spiller GA (1993) Handbook of Dietary Fiber in Human Nutrition. Boca Raton, FL: CRC Press Inc.

Spiller GA, Story JA, Wong LG, Nunes JD, Alton M, Petro MS, Furumoto EJ, Whittam JH \& Scala J (1986) Effect of increasing levels of hard wheat fiber on fecal weight, minerals and steroids and gastrointestinal transit time in healthy young women. Journal of Nutrition 116, 778-785.

Svanberg SJM, Gustafsson KBH, Suortti T \& Nyman EMGL (1995) Molecular weight distribution, measured by HPSEC, and viscosity of water-soluble dietary fiber in carrots following different types of processing. Journal of Agricultural and Food Chemistry 43, 2692-2697.

Tominaga S, Hirayama M, Adachi $\mathrm{T}$, Tokunaga $\mathrm{T}$ \& Iino $\mathrm{H}$ (1999) Effects of ingested fructooligosaccharides on stool frequency in healthy female volunteers: a placebo-controlled study. Bioscience Microflora 18, 49-53.

Van Dokkum W, Wezendonk B, Srikumar TS \& van den Heuvel EG (1999) Effect of nondigestible oligosaccharides on largebowel functions, blood lipid concentrations and glucose absorption in young healthy male subjects. European Journal of Clinical Nutrition 53, 1-7.

Wolever TM, Spadafora P \& Eshuis H (1991) Interaction between colonic acetate and propionate in humans. American Journal of Clinical Nutrition 53, 681-687. 